\title{
Inclusão pelo trabalho: participação de um indivíduo com Síndrome de Asperger em atividades de uma instituição de ensino
}

Inclusion through work: participation of an individual with Asperger's Syndrome in activities of an educational institution

Inclusión a través del trabajo: participación de una persona con síndrome de Asperger en actividades de una institución educativa

Recebido: 09/02/2021 | Revisado: 14/02/2021 | Aceito: 15/02/2021 | Publicado: 22/02/2021

Eduardo Cardoso Melo

ORCID: https://orcid.org/0000-0002-1323-5859 Instituto Federal de Educação, Ciência e Tecnologia de Minas Gerais, Brasil E-mail: eduardo.melo@ifmg.edu.br

Charles Tim Batista Garrocho

ORCID: https://orcid.org/0000-0001-8245-306X Instituto Federal de Educação, Ciência e Tecnologia de Minas Gerais, Brasil E-mail: charles.garrocho@ifmg.edu.br

Francismara Fernandes Guerra

ORCID: https://orcid.org/ 0000-0001-7713-3619 Instituto Federal de Educação, Ciência e Tecnologia de Minas Gerais, Brasil

E-mail: francismara.fernandes@ifmg.edu.br

\begin{abstract}
Resumo
$\mathrm{O}$ mercado de trabalho possui diversificadas demandas em termos de profissionais, ao mesmo tempo que as pessoas buscam qualificação para conseguir um local onde suas capacidades possam ser aplicadas e valorizadas. Entretanto, as pessoas com deficiências e transtornos normalmente enfrentam sérias dificuldades e preconceitos para ingressarem no mercado de trabalho e desenvolverem plenamente sua autonomia. No Brasil, a Lei 8.213/91 (também chamada de Lei das Cotas) prevê que, em empresas com 100 ou mais empregados, pessoas com deficiência ocupem de 2 a $5 \%$ das vagas nas empresas. Neste contexto marcado pela necessidade de integração de indivíduos no mercado de trabalho e pela demanda da aplicação da Lei das Cotas, o objetivo deste artigo é apresentar como foi a participação de um indivíduo com Síndrome de Asperger em um ambiente real de trabalho durante a execução de diversas atividades. O indivíduo é aluno regular da Associação de Pais e Amigos dos Excepcionais (APAE) da cidade de Bambuí/MG e participa desde 2017 de um programa especial de capacitação em ferramentas de informática no próprio laboratório da instituição. As atividades foram realizadas pelo aluno no Instituto Federal de Minas Gerais (IFMG), Campus Bambuí, durante duas semanas e possibilitaram ao mesmo aplicar diversos conteúdos estudados previamente na capacitação oferecida, bem como auxiliaram na melhoria da sua autonomia e autoconfiança.
\end{abstract}

Palavras-chave: Transtorno do espectro autista; Síndrome de Asperger; Inclusão; Mercado de trabalho.

\begin{abstract}
The job market has diverse demands in terms of professionals, at the same time that people seek qualification to find a place where their skills can be applied and valued. However, people with disabilities and disorders usually face serious difficulties and prejudices to enter the labor market and fully develop their autonomy. In Brazil, Law 8,213/91 (also called the Quota Law) provides that, in companies with 100 or more employees, people with disabilities occupy 2 to $5 \%$ of vacancies in companies. In this context marked by the need for integration of individuals in the labor market and the demand for the application of the Quota Law, the objective of this article is to present how was the participation of an individual with Asperger Syndrome in a real work environment during the execution of various activities. The individual is a regular student of the Association of Parents and Friends of the Exceptional (APAE) in the city of Bambuí/MG and has been participating since 2017 in a special training program in computer tools in the institution's own laboratory. The activities were carried out by the student at the Federal Institute of Minas Gerais (IFMG), Campus Bambuí, for two weeks and made it possible to apply various contents previously studied in the training offered, as well as helping to improve their autonomy and self-confidence.
\end{abstract}

Keywords: Autism spectrum disorder; Asperger syndrome; Inclusion; Job market. 


\section{Resumen}

El mercado laboral tiene diversas demandas en cuanto a profesionales, al mismo tiempo que las personas buscan cualificarse para encontrar un lugar donde se puedan aplicar y valorar sus habilidades. Sin embargo, las personas con discapacidad y trastornos suelen afrontar serias dificultades y prejuicios para incorporarse al mercado laboral y desarrollar plenamente su autonomía. En Brasil, la Ley 8.213/91 (también llamada Ley de Cuotas) establece que, en empresas con 100 o más empleados, las personas con discapacidad ocupan del 2 al 5\% de las vacantes en las empresas. En este contexto marcado por la necesidad de integración de las personas en el mercado laboral y la demanda de la aplicación de la Ley de Cuotas, el objetivo de este artículo es presentar cómo fue la participación de una persona con Síndrome de Asperger en un entorno laboral real durante la ejecución de diversas actividades. El individuo es alumno habitual de la Asociación de Padres y Amigos de los Excepcionales (APAE) en la ciudad de Bambuí/MG y participa desde 2017 en un programa especial de capacitación en herramientas informáticas en el laboratorio propio de la institución. Las actividades fueron realizadas por el alumno en el Instituto Federal de Minas Gerais (IFMG), Campus Bambuí, durante dos semanas y permitieron aplicar diversos contenidos previamente estudiados en la formación impartida, además de contribuir a mejorar su autonomía y autogestión.

Palabras clave: Trastorno del espectro autista; Síndrome de Asperger; Inclusión; Mercado de trabajo.

\section{Introdução}

Os transtornos invasivos do desenvolvimento referem-se a um conjunto de condições marcadas pelo início precoce de atrasos e desvios no desenvolvimento de diversas habilidades, em especial aquelas sociais e comunicativas (Simpson, 2018). Como não se trata de um assunto simples e amplamente difundido na sociedade, o trato com pessoas que apresentam tais transtornos ainda é motivo de desconforto e, em alguns casos, até medo de reações inesperadas (Buemo et al, 2019). Após o autismo, a Síndrome de Asperger é o transtorno invasivo de desenvolvimento mais conhecido, incluída como um distúrbio no Manual Diagnóstico e Estatístico de Transtornos Mentais (American Psychiatric Association, 2013). A Síndrome de Asperger recebeu o nome de Hans Asperger, que em 1944, relatou quatro casos de crianças que exibiam inteligência e linguagem normais, mas preferiam brincar sozinhas e evitar a interação social. A deficiência na interação social é uma das principais características da Síndrome de Asperger, no qual inclui uma dificuldade com a reciprocidade socioemocional e a comunicação não verbal, como expressão facial, gestos e contato visual.

Segundo Mercadante et al. (2006), a origem de tais transtornos pode estar relacionada a fatores genéticos, entretanto a educação infantil também influencia no grau de vulnerabilidade, na questão social e na rigidez apresentados pelos portadores da Síndrome de Asperger. Além disso, de acordo com a Classificação Internacional de Doenças (OMS, 1993), uma das características mais marcantes das pessoas diagnosticadas com essa síndrome é seu interesse voltado a objetos mecânicos e eletrônicos, em detrimento do interesse pelos seres humanos. Em suma, "os portadores dessa síndrome possuem grandes habilidades intelectuais, são sábios, por isso, a necessidade de serem estimulados em suas áreas de habilidades específicas, dando aos mesmos condições e oportunidades de vivenciar sucessos em suas vidas profissionais” (Galdino, 2017, p.3).

De acordo com Klin (2006), ainda que sejam vitimizadas, crianças com essa síndrome conseguem assistir aulas normalmente com outras desde que exista o suporte individualizado de um profissional da educação e, nos casos em que a criança possua dificuldades de socialização e de comportamento, se ofereça a modalidade de educação especial. Pode-se dizer que, atualmente, há um caminho promissor para aqueles com Síndrome de Asperger, que os leva a serem capazes de utilizar seus talentos para obter trabalho e a terem vidas que não dependa do apoio de outras pessoas (Mcintosh, 2016).

Durante um projeto piloto desenvolvido pelo Instituto Federal de Minas Gerais, Campus Bambuí, em parceria com a Associação de Pais e Amigos dos Excepcionais (APAE) da mesma cidade, ofertaram-se diversos minicursos na área de informática para os alunos matriculados nesta última instituição. Dentre os participantes, destacou-se um jovem do sexo masculino, com 19 anos, aluno regular da APAE há 5 anos e com o Ensino Médio concluído, que apresenta quadro compatível com Transtornos Globais do Desenvolvimento, especificamente com a Síndrome de Asperger.

No seu cotidiano, ele possui dificuldade de atenção e concentração, situação que se reflete em problemas de organização de rotina e término incompleto de suas atividades. Em relação à fala, trata-se de um indivíduo que no começo das 
capacitações verbalizava apenas o necessário, sendo notória sua melhoria nos últimos anos. O aluno participou dos cursos desde o início da oferta, demonstrando sempre muito interesse no funcionamento do processador de texto e em edição de fotos e vídeos. Foi um dos alunos mais frequentes, estando presente em média em duas aulas semanais. Os pais relatam que o aluno se mostra muito interessado no uso do computador, embora apresente dificuldade de concentração em uma mesma tarefa por muito tempo, o que faz com que não consiga concluí-la. Nas capacitações, ele conseguiu executar com relativa tranquilidade e facilidade as tarefas que lhe foram atribuídas, desde que fossem do seu interesse. Já aquelas que não despertaram sua atenção foram simplesmente desconsideradas pelo mesmo, como se não tivessem sido apresentadas.

Surgiu daí a ideia de se oferecer um estágio não remunerado para esse aluno como um meio de se colocar em prática as atividades aprendidas, tal como entender e superar as dificuldades da capacitação e da introdução dos indivíduos com Síndrome de Asperger no mercado de trabalho. Esse tipo de oportunidade é fundamental para avaliar o comportamento desses indivíduos nas rotinas de uma empresa e, consequentemente, uma forma construir ambientes adequados que facilitem esse processo.

\section{Trabalhos Relacionados}

Encontrar trabalhos que se propõem a investigar a empregabilidade de pessoas com Autismo é mais comum do que estudos sobre pessoas com Síndrome de Asperger. Encontrar um emprego é um processo confuso e provocador de ansiedade para muitos indivíduos com esta síndrome que, por sua vez, podem não saber que estão qualificados e ainda apresentam dificuldade para comunicar seu valor aos empregadores (Simone e Grandin, 2010). É necessário trabalhar os pontos fortes desses indivíduos, desenvolver o marketing pessoal e também melhorar aspectos de confiança e entusiasmo (Bissonnetee, 2012).

Em um guia aos empregadores, Bissonnetee (2008) apresenta meios de como utilizar os talentos dos indivíduos com Síndrome de Asperger, visto que são uma força de trabalho capaz, inteligente e subutilizada. Já Lorenz e Heinitz (2014) apresentam uma visão geral sobre os indivíduos com Síndrome de Asperger, cujos resultados apontam uma auto eficácia geral e ocupacional mais baixa, porém sugerem que tais indivíduos podem se beneficiar de programas de treinamento que visam especificamente um aumento na auto eficácia ocupacional.

Ao investigar a empregabilidade, Nesbitt (2000) sugere que muitos dos itens classificados, em geral, como importantes para setores de recursos humanos estavam relacionados a áreas (por exemplo, comunicação e interação social) que normalmente podem ser difíceis para um indivíduo com Síndrome de Asperger lidar devido ao fato de terem uma compreensão muito literal da linguagem. Além disso, os resultados também apontam que as organizações que não empregam um indivíduo com esta síndrome se concentraram mais em itens relacionados à capacidade do indivíduo de se comportar de certas maneiras esperadas, tais como ser sensível, se relacionar em grupos, expressões faciais, e entender conceitos abstratos.

Os trabalhos de Koegel et al. (2013) e Mynatt, Gibbons e Hughes (2014) investigaram a introdução de indivíduos com Síndrome de Asperger na faculdade. Após as intervenções, observou-se um aumento no número de eventos sociais frequentados por semana. Além disso, todos os questionários de qualidade de vida e satisfação relataram uma satisfação maior com a experiência na faculdade e as interações entre pares após a intervenção. Entretanto, os resultados também apontam que alunos com síndrome de Asperger enfrentam sintomatologia complexa, como dificuldade em habilidades sociais, interesses restritos, problemas sensoriais e falta de autoconsciência que podem afetar sua capacidade de concluir a faculdade e entrar com sucesso na força de trabalho. 


\section{Contextualização do Projeto Desenvolvido na APAE}

Desde o início do ano de 2017, o Campus Bambuí do Instituto Federal de Minas Gerais (IFMG) possui uma parceria com a Associação de Pais e Amigos dos Excepcionais (APAE) da cidade para oferta de capacitação em recursos de informática aos alunos desta entidade assistencial. O objetivo principal desta parceria é preparar esse público para realizar atividades diversas que requerem o uso de tecnologias computacionais simples, como elaboração de documentos em processadores de texto, controle de informações em planilhas eletrônicas, edição básica de imagens e vídeos e pesquisas na internet. Como a APAE atua no sentido de promover em seus alunos maior autonomia, essa capacitação visa colaborar com os envolvidos na melhoria de sua relação com os diversos recursos de informática com os quais as pessoas se deparam a todo momento do dia.

Ao considerar a realidade vivida pelos atendidos das APAEs, constata-se que eles apresentam necessidades muito específicas, o que faz com que seu aprendizado também seja diferente e demande aplicações de metodologias de ensino diferenciadas. Neste contexto, a parceria da APAE com o IFMG compreende a realização de um curso com aulas semanais em um laboratório de informática próprio da entidade, composto atualmente por 10 computadores conectados à internet e com programas básicos instalados, como pacotes de escritório e navegador. A capacitação não requer presença obrigatória semanal dos alunos, pois há outras oficinas oferecidas como parte da programação da entidade, sobre a qual cada um tem a liberdade para escolher o que deseja fazer no dia. Cada aula tem duração de uma hora, sendo realizada três vezes por semana a fim de permitir que um número maior de alunos possa participar. O grande diferencial é que os conteúdos trabalhados com cada aluno são específicos, isto é, personalizados de acordo com seu interesse e capacidade.

As aulas são conduzidas pelos monitores, que são estudantes voluntários do IFMG Campus Bambuí, oriundos dos cursos de Técnico em Informática e Bacharelado em Engenharia de Computação. A seleção dos estudantes é feita com base em entrevistas com o coordenador da parceria, objetivando identificar principalmente a aptidão e capacidade de interação do candidato em lidar com o público específico da APAE. Ao final de cada aula, os monitores registram a relação de participantes, os conteúdos trabalhados com cada um e os resultados obtidos. Ao término do mês é feita uma reunião na qual é discutido a respeito do aproveitamento dos alunos nas aulas e como elas podem ser melhoradas a partir dos resultados alcançados, das impressões dos próprios alunos e dos professores da entidade. Até o presente momento esta parceria auxiliou na capacitação de 55 diferentes alunos da APAE de Bambuí.

\section{Metodologia}

\subsection{Caracterização da pesquisa}

De acordo com Gerhardt e Silveira (2009), esta pesquisa pode ser classificada sob diversos aspectos. Em relação à sua abordagem, trata-se de um estudo qualitativo no qual buscou-se, sob o ponto de vista dos pesquisadores, aprofundar o entendimento sobre a atuação do indivíduo com Síndrome de Asperger no ambiente de trabalho em questão. No que se refere à natureza, tem-se uma pesquisa básica sem aplicação prática diretamente prevista, mas que pode ser replicada em contextos e objetivos similares. Quanto aos objetivos, a pesquisa é exploratória por buscar ampliar os conhecimentos sobre o tema em questão, de forma que um número maior de pessoas passe a ter familiaridade com o mesmo. Sobre os procedimentos, o trabalho pode ser caracterizado como um estudo de caso, pois envolve um situação bem definida, assim como focaliza a análise sobre um indivíduo específico.

\subsection{Roteiro da pesquisa}

A partir do ano de 2019, a parceria APAE-IFMG passou a trabalhar com o objetivo adicional de realizar capacitação em recursos de informática com vistas a auxiliar os alunos da entidade que porventura venham a trabalhar em empresas da cidade. Como se trata de uma mudança conceitual significativa em relação à proposta inicial da parceria, optou-se pela criação 
de um projeto piloto de estágio exclusivo, pensando-se na capacitação para o mercado de trabalho. A primeira ação realizada foi uma reunião com a Diretoria da APAE para analisar o perfil dos alunos participantes da capacitação nos anos anteriores para identificar aqueles com interesse e capacidade de atuação em empresas. Com base nesta análise prévia, foram identificados cinco potenciais alunos participantes, os quais foram convocados para uma reunião individual. Dos cinco entrevistados, apenas dois se mostraram interessados com a proposta.

A etapa seguinte consistiu na realização de uma reunião com os pais destes alunos, na qual foi explicada a proposta do projeto piloto e como seriam conduzidas as atividades durante a sua execução. Enquanto uma das famílias se mostrou reticente com a participação de sua filha no projeto, optando por aguardar os resultados desta primeira execução, a outra família se mostrou muito receptiva à ideia e incentivou plenamente a participação de seu filho nas atividades, se dispondo a auxiliar ativamente no que se mostrasse necessário.

Por questões de facilidade de acesso e possibilidade de acompanhamento mais próximo pelo coordenador da parceria, optou-se pela realização das atividades práticas no Campus Bambuí do IFMG. Com base nos conteúdos já trabalhados pelo aluno (chamado de estagiário a partir deste momento) durante as capacitações feitas na APAE, seu perfil e considerações feitas pelos professores e pela diretoria da APAE, foi conduzido um planejamento de quais atividades seriam realizadas durante o período de execução do projeto piloto. Definiu-se que as atividades estariam relacionadas com rotinas da coordenação do curso Técnico em Informática e participação em aulas da disciplina Informática Básica oferecida para vários cursos do IFMG no Campus Bambuí. Ficou definido, ainda, que um dos monitores que atuou nas capacitações feitas na APAE também participaria do projeto piloto acompanhando o estagiário nas aulas de informática no Campus.

\section{Execução das Atividades do Projeto Piloto}

No primeiro dia de atividades o estagiário foi levado diretamente à sala da coordenação, momento no qual foram explicadas de maneira breve e objetiva algumas das tarefas realizadas rotineiramente pelo coordenador do curso. Em seguida, ele acompanhou o coordenador em uma visita nas salas de aula do curso, momento no qual foi apresentado aos discentes e sua presença na instituição foi informada. $\mathrm{O}$ estagiário também compareceu à sala dos professores, tendo sido apresentado a todos os presentes no momento, inclusive ao professor responsável pela disciplina de Informática Básica. Ao retornar à sala da coordenação, foi passada a primeira atividade que consistia na elaboração de uma planilha eletrônica contendo o nome de todos os alunos do curso que participariam de uma visita técnica a uma empresa da região. A lista de nomes estava preenchida a caneta e o estagiário criou uma planilha com todos os dados solicitados pelo setor responsável por eventos externos. Para a realização desta atividade o coordenador auxiliou apenas na inserção do logotipo do campus no documento. Ainda no primeiro dia, foram visitados os laboratórios de informática onde acontecem as aulas práticas das disciplinas do núcleo técnico do curso.

No segundo dia de atividades, o estagiário participou junto com o coordenador de uma reunião com os representantes de turma, na qual os assuntos discutidos foram registrados de forma manuscrita em papel. Foi passada a tarefa de digitar este conteúdo em um documento utilizando o mesmo processador de texto estudado na capacitação na APAE. O estagiário apresentou facilidade na execução da tarefa, tendo concluído a formatação do documento totalmente por conta própria utilizando os recursos de estilização do processador de texto.

A atividade planejada para o terceiro dia no campus era a edição de imagens das três turmas do curso para posterior impressão em um convite de evento interno. O estagiário se mostrou interessado na tarefa assim que ela foi apresentada. Utilizando um editor online de imagens, tal qual havia sido utilizado na capacitação na APAE, ele aplicou diversos efeitos nas imagens e ficou totalmente imerso na realização da tarefa. Quando a edição das imagens foi finalizada, o coordenador fez a impressão das mesmas e levou-as para os alunos das turmas visualizarem o resultado, o qual foi aprovado por todos.

No quarto dia de atividades o estagiário foi instruído a elaborar uma planilha eletrônica contendo informações de 
diversos itens que seriam orçados pelo campus para aquisição e posterior utilização nas aulas práticas de redes de computadores. Como essas informações estavam em um sistema interno, ele necessitou trabalhar com duas janelas de aplicativos abertas ao mesmo tempo no computador, fato que dificultou um pouco seu desempenho em questão de tempo, não de qualidade. A planilha continha o nome e a descrição de cada produto a ser comprado, a quantidade necessária e o valor unitário (obtido no sistema interno). Foi solicitado ao mesmo que criasse uma coluna com fórmula para calcular o valor total de cada item, o que foi feito com auxílio do coordenador. Em seguida, ele ainda criou outras fórmulas para cálculos diversos não previstos inicialmente na planilha.

No último dia de atividades relacionadas com a coordenação do curso Técnico em Informática estava prevista a elaboração no processador de texto de um cartaz informativo para ser afixado nos laboratórios, porém o estagiário não quis realizar a tarefa alegando que "isso não era muito difícil para ele". O coordenador conversou com ele e outra atividade foi proposta para o mesmo, a edição de um pequeno vídeo com os melhores momentos de um evento interno realizado no campus semanas antes. Dados dois vídeos com duração entre um e dois minutos cada, o estagiário foi instruído a editar um vídeo curto de no máximo um minuto contendo imagens diversas que, na visão dele, apresentassem o evento. No início, ele se mostrou muito focado na realização da tarefa e selecionou as partes que mais lhe interessou em cada um dos vídeos, mas após apresentar dificuldades para operacionalizar uma função do programa, seu interesse foi diminuindo até que o coordenador lhe auxiliou na resolução do problema e o vídeo pôde ser finalizado.

Na semana seguinte, como planejado, o estagiário deveria participar como monitor em aulas da disciplina Informática Básica em um laboratório que dispunha de 35 computadores. O professor responsável pela disciplina já havia sido envolvido no projeto com a devida antecedência e também o acompanhou durante sua participação nas aulas.

As aulas do primeiro dia tratavam sobre criação de tabelas no processador de texto. Quando qualquer aluno regular apresentava uma dúvida para o professor, o estagiário era levado até lá para que pudesse escutar do que se tratava e propor alguma solução. No início, ele se mostrou um pouco incomodado com o grande número de alunos no laboratório e com o barulho produzido por eles, tendo saído do ambiente e ficado do lado de fora durante alguns minutos. Em seguida, retornou e conseguiu participar da resolução da dúvida de diversos alunos sobre diferentes atividades relacionadas ao processador de texto. Foi notório o aumento da sua confiança, que passou a andar com mais desenvoltura pelo laboratório e conseguiu resolver outras dúvidas apresentadas pelos presentes.

As atividades previstas para o segundo dia desta semana não puderam ser realizadas, pois o estagiário precisou viajar com o intuito de comparecer a uma consulta médica agendada de última hora pela sua mãe.

No dia seguinte as atividades foram realizadas em aulas com duas turmas e em laboratórios localizados em prédios diferentes dentro do campus. O tema da primeira aula era inserção de imagens em um documento de texto. As imagens deveriam ser baixadas da internet e inseridas pelos alunos em diversas formatações dentro do documento. Novamente a mesma metodologia do primeiro dia foi aplicada e o estagiário era chamado para tentar auxiliar na resolução das dúvidas dos alunos regulares. Neste momento o estagiário se mostrou bem participativo e solícito, verbalizando bem a resolução das questões que lhe foram apresentadas. Ele, inclusive, auxiliou diversos alunos a fazer o download das imagens para o computador antes de inseri-las no documento de texto. $\mathrm{O}$ tema da segunda aula era sobre formatação de textos em colunas. Como este era um assunto que o estagiário não dominava ou pelo menos não mostrou interesse, nenhuma dúvida teve seu auxílio direto.

No quarto dia de aulas, o assunto abordado era criação de fórmulas em planilhas eletrônicas. Quando foi apresentado para o estagiário, ele logo mencionou a fórmula que havia aprendido a criar na semana anterior quando estava realizando uma tarefa na coordenação do curso Técnico em Informática. Por se tratar de uma funcionalidade relativamente simples de ser executada no programa para a turma, nenhuma dúvida foi levantada. Neste momento o estagiário se sentou em um dos computadores disponíveis no laboratório e resolveu, por conta própria, fazer a mesma atividade proposta para a turma, tendo 
conseguido implementá-la sozinho.

Para o último dia de atividades, estavam previstas aulas sobre edição de imagens. Para tanto, o professor optou por utilizar a mesma ferramenta online das capacitações da APAE, de maneira que o estagiário pudesse auxiliar a turma quanto às dúvidas que surgissem. O professor apresentou o funcionamento básico da ferramenta, pediu aos participantes que fizessem o download de uma imagem e aplicassem efeitos e inserção de textos na mesma para alterá-la. $\mathrm{O}$ aluno do projeto se mostrou bastante interessado em visualizar as imagens que a turma estava trabalhando, passando de computador em computador para analisá-las. Em determinadas imagens ele sugeriu melhorias, como aplicação de filtro preto e branco e correção do brilho.

\section{Considerações Finais}

A despeito da curta duração do estágio, a participação do indivíduo com Síndrome de Asperger nas atividades planejadas foi bastante proveitosa. Praticamente todas as tarefas previstas inicialmente foram realizadas, mesmo que com ajustes pontuais durante a execução do projeto. $\mathrm{O}$ estagiário se mostrou, na maioria das vezes, bastante interessado em saber como os trabalhos são realizados na escola, sendo possível apresentar a ele a aplicabilidade do que fora estudado nas capacitações realizadas no laboratório da APAE. A família do estagiário relatou que o mesmo se mostrou muito entusiasmado com sua participação no projeto, apresentando ainda interesse em conseguir um emprego para trabalhar com informática e continuar aprendendo sobre esta área. Em uma reunião realizada após o encerramento do projeto, ele reforçou esta intenção de atuar na área, indicando que a participação nas aulas e nas atividades práticas o ajudou a se relacionar melhor com as pessoas e entender o que desejam ao utilizar os recursos de informática.

As principais dificuldades enfrentadas durante a condução dos trabalhos estão relacionadas com a operacionalização da participação do estagiário nas atividades práticas e com a conscientização dos alunos da disciplina Informática Básica no sentido de compreenderem a realidade vivida por ele e como aquele momento seria importante para seu crescimento pessoal. Neste sentido, há de destacar que o apoio da família foi fundamental para que o estagiário pudesse estar presente no campus em praticamente todos os dias planejados. Além disso, o professor envolvido no projeto piloto teve papel de destaque ao conduzir sessões de conversas com as turmas apresentando o projeto e o perfil do estagiário.

Por fim, sugere-se a condução de novos projetos envolvendo indivíduos com o perfil apresentado neste estudo de maneira a ampliar a compreensão sobre como eles podem contribuir com as organizações a partir de uma ótica diferente.

\section{Referências}

American Psychiatric Association. (2013). Diagnostic and statistical manual of mental disorders. BMC Med, 17 (1), 133-137. encurtador.com.br/ntAH9

Bissonnetee, B. (2008). The Employers Guide to Asperger's Syndrome. http://www.forwardmotion.info/wp/wp-content/uploads/2015/06/Employers-Guide-toAspergers-Syndrome.pdf

Bissonnetee, B. (2012). The Complete Guide to Getting a Job for People with Asperger's Syndrome: Find the Right Career and Get Hired. Jessica Kingsley Publishers.

Buemo, B., Alli, F., Iracet, J. V., Ribas, L., Pereira, R., Kruel, C. S., Guazina, F. M. N., \& Carlesso, J. P. P. (2019). Autismo no Contexto Escolar: A Importância da Inserção Social. Research, Society and Development, 8(3), e2783822. https://doi.org/10.33448/rsd-v8i3.822

Galdino, L. S. (2017). Síndrome de Asperger: Intervenções na Abordagem Cognitivo Comportamental. Psicologado. encurtador.com.br/eyACI

Gerhardt, T. E., \& Silveira, D. T. (2009). Métodos de Pesquisa. Editora da UFRGS.

Klin, A. (2006). Autismo e síndrome de Asperger: uma visão geral. Revista Brasileira de Psiquiatria, 28 (1), 3-11. 10.1590/S1516-44462006000500002.

Koegel, L. K, et al. (2013). Increasing socialization in adults with Asperger's syndrome. Psychology in the Schools, 50 (9), 899-909. 10.1002/pits.21715.

Lorenz, T., \& Heinitz, K. (2014). Aspergers-different, not less: occupational strengths and job interests of individuals with Asperger's Syndrome. PloS one, 9 (6), 100-358. 10.1371/journal.pone.0100358. 
Research, Society and Development, v. 10, n. 2, e44110212821, 2021

(CC BY 4.0) | ISSN 2525-3409 | DOI: http://dx.doi.org/10.33448/rsd-v10i2.12821

Mcintosh, C. (2016). Asperger's syndrome and the development of a positive work identity. Journal of Business and Management, 22 (1), 87-101. encurtador.com.br/cwBCW

Mercadante, M. T., Van Der Gaag, R. J., \& Schwartzman, J. S. (2006). Transtornos invasivos do desenvolvimento não-autísticos: síndrome de Rett, transtorno desintegrativo da infância e transtornos invasivos do desenvolvimento sem outra especificação. Revista Brasileira de Psiquiatria, 28 (1), 12-20. $10.1590 /$ S1516-44462006000500003.

Mynatt, B. S., Gibbons, M. M., \& Hughes, A. (2014). Career development for college students with Asperger's syndrome. Journal of Career Development, 41 (3), 185-198. 10.1177/0894845313507774.

Nesbitt, S. (2000). Why and why not? Factors influencing employment for individuals with Asperger syndrome. Autismo, 4 (4), $357-369$. $10.1177 / 1362361300004004002$.

OMS (Organização Mundial da Saúde). (1993). Classificação de transtornos mentais e de comportamento da CID-10: descrições clínicas e diretrizes diagnósticas. Porto Alegre: Artmed.

Simone, R., \& Grandin, T. (2010). Asperger's on the job: Must-have advice for people with Asperger's or High Functioning Autism, and their employers, educators, and advocates. Future Horizons.

Simpson, D. (2018). Asperger's syndrome and autism: Distinct syndromes with important similarities. Routledge, 1 (1), 25-38. 10.4324/9780429482380. 